\title{
Teaching Scientific and Professional Ethics: A Model of Graduate Student Training from Psychology
}

\author{
Rose A. Sevcik, Julia Perilla \\ Department of Psychology, Georgia State University, Atlanta, Georgia, USA
}

Email address:

rsevcik@gsu.edu (R. A. Sevcik)

\section{To cite this article:}

Rose A. Sevcik, Julia Perilla. Teaching Scientific and Professional Ethics: A Model of Graduate Student Training from Psychology. Humanities and Social Sciences. Special Issue: Ethical Sensitivity: A Multidisciplinary Approach. Vol. 4, No. 2-1, 2016, pp. 25-28. doi: 10.11648/j.hss.s.2016040201.14

Received: November 1, 2015; Accepted: February 2, 2016; Published: May 13, 2016

\begin{abstract}
As individuals engage in research and/or clinical practice, reference to, and guidance from, their professional codes of ethics permeates their work. There has been a rise in the number of web sites, workshops, and publications about ethical training and behavior. Increasingly, courses have been developed for students at the graduate level along with up to date content provided in the form of continuing education activity for professionals in practice. Contemporary approaches to ethics training have moved away from rule-governed practices to developing ethical decision frameworks. In addition, recognizing the character of the professional has become essential. Acknowledging the influences on developing students' professional identities is fundamental to their graduate training. The purpose of this article is to illustrate one such approach to graduate training in ethics.
\end{abstract}

Keywords: Ethical Decision Making, Doctoral Education, Ethics Training

\section{Introduction}

As individuals engage in research and/or clinical practice, reference to, and guidance from, their professional codes of ethics permeates their work. From medicine to business, professional codes of ethics assert the principles and standards expected from its practicing professionals. There has been a rise in the number of web sites, workshops, and publications about ethical training and behavior Increasingly, courses in ethics have been developed for students at the graduate level of training along with up to date content provided in the form of continuing education activity for professionals in practice. Contemporary approaches to ethics training have moved away from rule-governed practices to developing ethical decision frameworks (e.g., $[1,2])$. In addition, recognizing the character of the professional has become essential. Acknowledging the influences on developing students' professional identities is fundamental to their graduate training.

The purpose of this article is to illustrate one such approach to graduate training in ethics. At Georgia State University's Department of Psychology, we have developed a course in scientific and professional ethics in psychology with the goal of offering doctoral level graduate students an introduction to the ethical standards of, and ethical issues within, psychology as a science and a profession. Issues within the domains of research, teaching, and practice were emphasized. Contemporary influences on the ethical behavior of psychologists in training were offered.

\section{Course Model}

The design of the semester-long course included a strong emphasis on ethical decision-making with an eye to ensuring that the students had a framework that they may use when confronted with dilemmas both in their training and in their professional lives. This format was taken to move away from an emphasis on a specific professional code of ethics and to offer information and an approach that could be applied more broadly. Included as a course objective was the opportunity for students to learn about and apply ethical guidelines while obtaining experience with identifying ethical concerns that impact psychologists. Doctoral students also take on multiple roles in their training. In addition to their student status, they are researchers in training learning about the conduct of a 
specific type and method of study. In their program of research, they may find themselves mentoring other students who are less experienced than they are. Students, depending on their area of concentration, may be a practitioner in training, a student supervised by a licensed professional and offering assessment or therapeutic services or they may be an instructor in an undergraduate class. In each of these roles, students have responsibilities to themselves, to the persons with whom they may be conducting research, delivering services, or instructing in an educational context, all of which can present ethical issues.

Two department faculty members/staff, with distinct areas of training and expertise, co-teach the course. One faculty member has been trained in developmental and comparative psychology while the second faculty member's training is in the areas of clinical and community psychology. We have more than 10 years of experience in delivering this course. The course was required for all doctoral students within the department. Approximately 120 students make up the doctoral training program in which they focus their training in one of eight different concentrations (e.g., clinical, developmental, community, among others). This range of interests and skills contribute to the breadth of the class and its interactions since students may approach an issue from distinct programmatic perspectives. Students may enter a program after completing their baccalaureate or a master's degree. No separate, terminal master's degree program is offered within the department.

\subsection{Topics}

Included among the major topics presented in the course were essential constructs in ethical decision-making. The course began with a consideration of the history and development of the American Psychological Association Code of Ethics [3]. We interwove the model of ethical decisionmaking within this treatment of the code. Kitchener [1] has offered a two level approach to decision-making. The first recognizes an individual's immediate response to a situation relying upon one's personal history of values and experiences. The second level of evaluation, labelled as critical-evaluation, incorporates external guidance such as professional codes built upon principles such as beneficence (do good) and nonmaleficence (do no harm) among others. The interplay of these and other principles, such as autonomy and justice are examined in the constructs of confidentiality, informed consent, conflict of interest, and professional competence. The contexts in which these and other constructs are important include research, teaching, and practice. Other specialized situations include issues that apply to multiple role relationships and the issues of power differentials, boundaries, and exploitation. The topic of social justice also was explored with both historical and contemporary illustrations.

\subsection{Course Activities}

The faculty members' own training and expertise was supplemented with strategically invited guest lecturers.
Faculty from the Department of Philosophy and the university's Ethics Center, for example, allowed the students to interact with individuals who have very distinct knowledge bases and experiences to offer in the analyses of ethical issues. Faculty from the College of Law shared their unique perspectives on ethical dilemmas in the context of health, behavior, and society, and offered important distinctions between ethics and the law. In addition, some psychology department faculty also joined us offering their views in distinct contexts such as social justice in contexts around the world. We also hosted presentations by staff members who direct the administration of research at the university level. These staff are responsible, for example, for the compliance issues that govern human (Institutional Review Board: IRB) and nonhuman animal (Institutional Animal Care and Use Committee: IACUC) research such as permissions to conduct research. We also invited annually a panel of more advanced doctoral students and/or newly minted post-doctoral graduates so that they could reflect on and share with the class members their own experiences with ethical challenges as students and new professionals. The student panel typically presented some of the most challenging situations discussed within the term, reflecting situations that many students may encounter during their training.

In addition to exploring the course content, students were engaged in case analyses. Cases were drawn from a range of sources including contemporary articles within the news media, cases available from university associated experts (e.g., University of Indiana's Poynter Center [4]), and cases created by the instructors themselves. Ensuing discussions centered on identifying ethical dilemmas and issues, determining the underlying principles, examining the affected stakeholders, and considering alternative decisions and their outcomes.

The students' coursework was planned around four major assignments: 1) writing an ethics autobiography; 2) interviewing a mentor about his/her own experiences with ethical dilemmas, 3) preparing and delivering a group presentation that delves deeply into a topic of their own interest (e.g., animal research/animal rights, child welfare, or cyberethics), and 4) completing a final examination. Participation in class discussions, preparing questions for discussion based on the week's reading assignments, including taking on the role of discussion leader, also was expected.

In the ethics autobiography assignment, students were asked to write about their own personal values [5] and how they related to their developing professional persona as psychologists in training. Bashe and colleagues [5] portray the acquisition of ethical behavior as a form of ethical acculturation emphasizing the integration of values as opposed to learning and following a set of rules. Reflecting on what and where the students' personal values derive (e.g., family, culture, society) was central to this assignment.

In the interview assignment, students were asked to communicate their vision of the key elements of their own burgeoning ethical framework. Their paper, written in a 
narrative form, included the ethical dilemmas and issues experienced and described by the interviewee. Attention to the standards articulated in the professional code of ethics (APA Code of Ethics, 2010, [3]) were required. The students also were asked to provide their own responses and reactions to the ethical scenarios that their mentors shared with them. In particular, we were interested in the students' view of their mentors' analyses, decisions, and actions in the dilemmas they offered. Finally, the students were asked to provide a description of their own developing framework in light of the information gleaned from the interview. The framework reflected the students' vision of the elements needed to assess challenges and/or issues and to guide their behavior. We viewed this assignment as aiding the students' development of their professional persona. We also saw the assignment as setting the stage for the mentor/mentee relationship in the context of professionals' expectation of ethical conduct. If students had not yet had that type of conversational exchange with their mentor, we hoped it would facilitate such a communication.

Students formed small groups around a topic of their interest in the third class assignment. Each member of the group had the responsibility to present one part of the group's material. A systematic exploration of issues and principles relevant to the selected topic was expected. Each group was expected to include the following parts: a statement of the problem, issue, or dilemma; examine relevant constructs such as confidentiality or consent; consider the impact of variable settings, if applicable; offer pro and con perspectives on the issue or dilemma; address the relationships of the elements to a formal model of ethical decision making; generate questions about the future of the issue. Group members also were responsible for engaging the other members of the class in a general discussion of the topic. We assessed both an individual and a group grade for each student. This assignment often unleashed great creativity among the students. Students have created mini talk shows to discuss and debate a topic, e.g., animal research versus animal rights. They have role played scenarios depicting distinct perspectives on issues of multi-cultural competence and explored issues surrounding research and practice with vulnerable populations such as individuals with developmental disabilities, from low resourced environments, or military veterans traumatized by war.

For the final comprehensive examination, students were asked to write a series of essays. Students were asked to carry out a comprehensive case analysis, examine in depth the standard surrounding a construct such as competence from different psychological sub areas and an emerging area, and flesh out the ethical framework they have developed during the term.

\subsection{Materials}

Two texts $[1,6]$ and several peer reviewed publications formed the reading materials for the course. The journal articles were divided into a required and supplementary reading list. These articles represented some classic ethics papers (e.g., [7] on the Tarasoff case and the duty to protect, i.e., protecting individuals from the threat of violence as opposed to maintaining client/ therapist confidentiality) along with some more recently published articles on current issues (e.g., [8] on using portable digital devices and privacy in psychotherapeutic services) in ethics. In addition, a list of electronic resources were provided made up of university ethics centers (e.g., Poynter Center, University of Indiana [4]), professional associations (e.g., Society for Research in Child Development [9]), and government entities (e.g., National Institutes of Health [10]). We also provided a list of guideline documents generated by the American Psychological Association. These guidelines addressed specific aspects of practice in the discipline of psychology such as using telepsychology, working with older adults, and multicultural education in varied contexts such as research and practice among many others. The links offered students a range of information sources on the topics of ethics, issues, and training.

\section{Course Outcomes}

Students' responses and feedback has been very positive. Students' performance in the course also has been excellent with students completing their assignments and participating in the class discussions.

Students provide evaluative comments on the course at the end of each term, completing both a numerical rating of aspects of the courser such as its organization, use of time, etc. Students also have the opportunity to write narrative comments about their assessment of the course and their experiences. They have frequently commented on the value of having two faculty in the co-teaching situation and the multiple perspectives offered by the guest speakers who visited class.

In addition, this course format and approach has been adopted as a model for faculty within other departments and other colleges for their own graduate training efforts in ethics.

\section{Conclusions}

Creating a course that centers on ethical decision making has provided a contemporary perspective on identifying and assessing ethical issues and dilemmas. Against the backdrop of a professional code of ethics, doctoral students are taught to consider their own personal values framed in the larger context of expected professional standards. Multiple perspectives and experiences are offered to engage the students in the training contexts in which they are immersed and allow them as well to consider their future training and development.

\section{Acknowledgements}

We thank the many students who participated in the class. We also acknowledge Dr. Martha Foster, Professor Emerita 
for her contributions to the original course design.

\section{References}

[1] K. S. Kitchener. (2000). Foundations of ethical practice, research, and teaching in psychology. Mahwah, NJ: Erlbaum.

[2] K. S. Kitchener, K S. and S. Anderson. (2010). Foundations of ethical practice, research, and teaching in psychology. Mahwah, NJ: Erlbaum.

[3] American Psychological Association http://www.apa.org/ethics/code/index.aspx.

[4] Indiana University: Poynter Center www.indiana.edu/ poynter/.

[5] A. Bashe, A., S. K. Anderson, M. M. Handesman, and R. R.
Kieyansky (2007). Acculturation model for ethics training: The ethics autobiography and beyond. Professional Psychology: Research and Practice, 38, 60-67.

[6] C. B. Fisher (2013). Decoding the ethics code: A practical guide for psychologists. Third edition. Thousand Oaks, CA. Sage Publications.

[7] P. S., Appelbaum, and A. Rosenbaum (1989). Tarasoff and the researcher: Does the duty to protect apply in the research setting? American Psychologist, 44, 885-894.

[8] D. O. Taube (2013). Portable digital devices: Meeting challenges to psychotherapeutic privacy. Ethics \& Behavior, 23, 80-97.

[9] Society for Research in Child Development: www.srcd.org.

[10] National Institutes of Health: http://ethics.od.nih.gov/topics.htm 